\title{
Mono-segment (segment 2) donor hepatectomy for pediatric liver transplantation
}

\author{
Rajan GARG*, Vinayak NIKAM, Anurag SHRIMAL, Prashantha S RAO, Mitul SHAH, Ravi MOHANKA \\ Department of Hepato-Pancreato-Biliary Surgery and Liver Transplantation, Global Hospitals, Mumbai, India
}

Introduction: Liver grafts are often reduced for pediatric liver transplant in infants to accommodate them in the child's abdomen and avoid portal hypoperfusion. However, the most common technique of non-anatomical reduction does not reduce graft thickness. We describe the technique of anatomical segment $2 \mathrm{graft}$ for liver transplant in an infant with acute liver failure.

Methods: A six-month-old child with acute liver failure required an emergency liver transplant in our unit. The child's mother was found medically suitable on pre-operative evaluation. However, the donor left lateral segment (LLS) was "blowfish" type with estimated GRWR of 3.5. The donor graft and recipient abdominal cavity measurements revealed that the donor's liver was too large for the child's abdominal cavity (distance from anterior abdominal wall to IVC-MHV-LHV confluence in the donor was $75 \mathrm{~mm}$ compared to $50 \mathrm{~mm}$ in the child).

Results: The dissection for LLS donor hepatectomy was performed using the standard technique followed by reducing segment 3 to obtain segment 2 graft, in-situ. The segment 3 pedicle was identified in the umbilical fissure and clamped. The ischemic plane was oblique, as demonstrated in the video, substantially reducing the graft thickness. Parenchymal transection was done using CUSA and the segment 3 pedicle and hepatic vein tributary were secured. The GRWR was 1.5 allowing good fit and primary closure of the child's abdomen. Post-operatively, the child had high transaminases (peak 2,000 IU/L) and high drain output $(2.5 \mathrm{~mL} / \mathrm{kg} / \mathrm{day}$ ) that settled down in a week.

Conclusions: The technique of anatomical mono-segment liver grafts is valuable for pediatric liver transplantation in. 